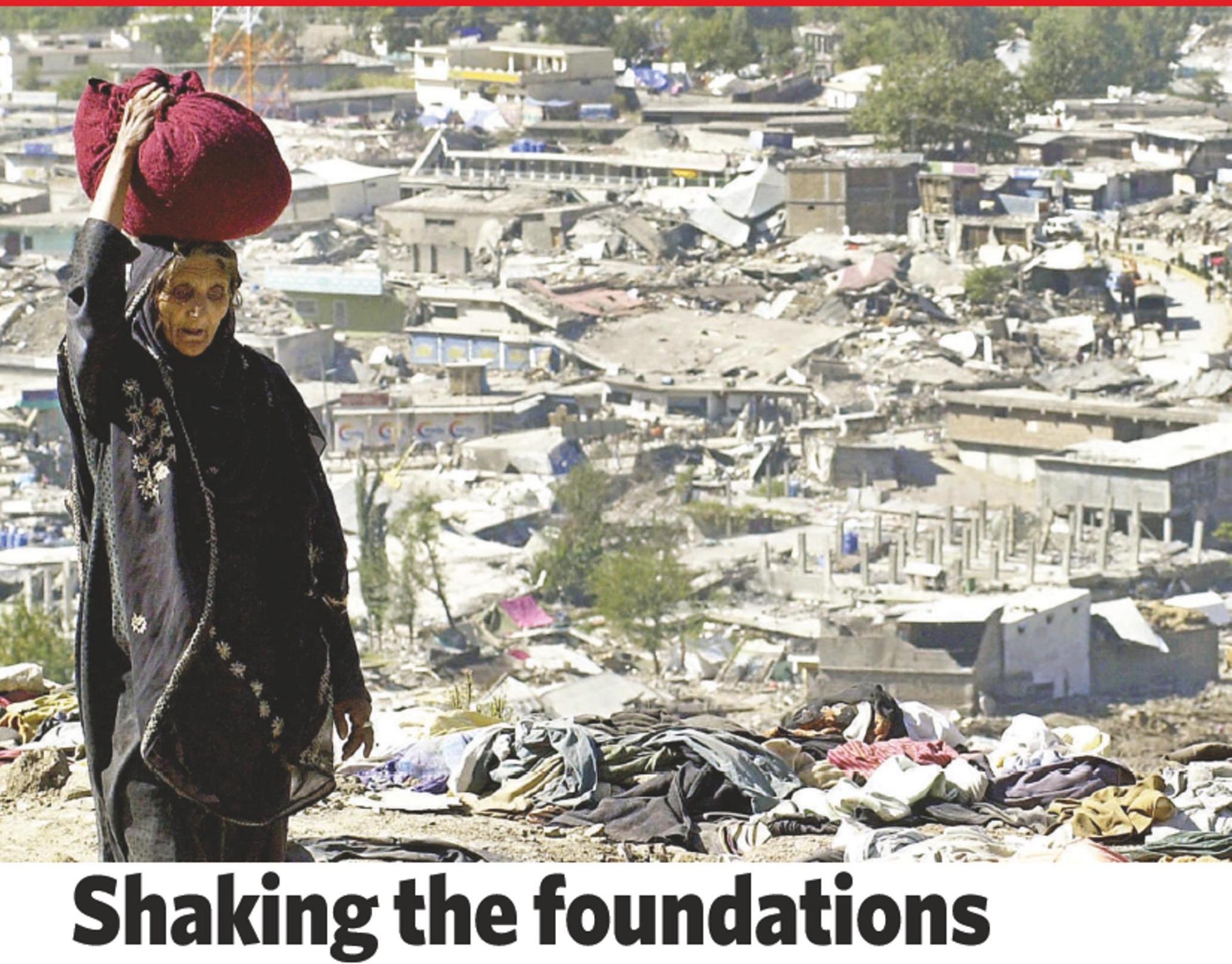

Last autumn's deadly earthquake caught Pakistan's government and scientific community off guard. Now a handful of officials and academics are struggling to bring the country up to code. Geoff Brumfiel reports from the scene.

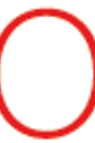
$\mathrm{n}$ the morning of Sunday 8 October, residents of Pakistan's capital, Islamabad, were shaken from their beds. The city was in the grip of an earthquake so violent that people could barely stand to flee. On the western side of town, a poorly constructed apartment building collapsed, killing dozens.

Closer to the quake's epicentre, the story was worse. In the northern city of Muzaffarabad, concrete buildings pancaked, killing their residents instantly. Massive landslides wiped out villages perched on steep mountain slopes, and falling rock severed the narrow highway that connects the mountainous region to the rest of the country. Phone lines were down, but rumours were flying. Some said nudear testing had caused the event.

The earthquake caught most Pakistanis off guard, says Khawaja Azam Ali, dean of the faculty of natural sciences at Quaid-i-Azam University in Islamabad. The last time Pakistan experienced a massively destructive earthquake was in 1935 , when the western city of Quetta was flattened, killing more than 30,000 people. This time, says $\mathrm{Ali}$, "knowledge about the earthquake risk was zero. There were simply not many people thinking about it."

That's surprising, because winding through the foothills just beyond Ali's office window is a geological fault hundreds of kilometres long. It is one of about half a dozen similar faults running more or less through the heart of Islamabad. They are a silent reminder that this troubled nation - home to grinding poverty, tribal insurgencies, radical Islam, and more than two dozen nuclear warheads - lies in one of the world's most seismically active regions.
In the wake of last October's disaster, which killed at least 73,000 people, a fledgling movement has emerged to prepare the nation for future earthquakes. The government has pledged millions of dollars to build a new seismic network, and local universities are ramping up programmes in seismology and earthquake engineering. But success will require a sea change in Pakistan's attitude towards seismic risk.

The nation's military government will have to release sensitive data that have remained hidden. Universities must train a new community of seismologists. And ultimately, ordinary people - many of them illiterate - will 8 have to be educated about how to survive quakes. This effort will take collaboration between the military, civilian government and educational institutions on a scale never before 
seen in the country. But it can be done, says Ali: "If there is such cooperation, then yes, there is a chance of progress."

The problem is formidable. Pakistan lies at the junction of three tectonic plates (see graphic). From the southeast, the Indian plate is sliding towards Afghanistan at some 40 millimetres each year, while from the southwest the Arabian plate moves northwards at a nearly identical dip. Caught in this geological pincer movement is a small promontory of the massive Eurasian plate. As the Indian and Arabian plates plough into Eurasia, they push up the Himalayan and Hindu Kush ranges in northern Pakistan, and a series of smaller ranges along its borders with Afghanistan and Iran. The enormous compression warps and tears the plates, creating hundreds of active faults throughout the country.

Nearly all of the major faults have been catalogued by the Geological Survey of Pakistan. But the survey did little beyond mapping each fault. To assess the danger, seismologists need a record of the tiny tremors that rattle the country almost daily. Collecting data from multiple seismic stations on those smaller quakes shows which faults are currently under stress.

Such 'microseismic' data have been collected for years by three public agencies: the Water and Power Development Authority, which oversees the nation's dams; the Atomic Energy Commission; and the Meteorological Department, which is formally responsible for seismic monitoring. But historically, that information has not been made public, according to

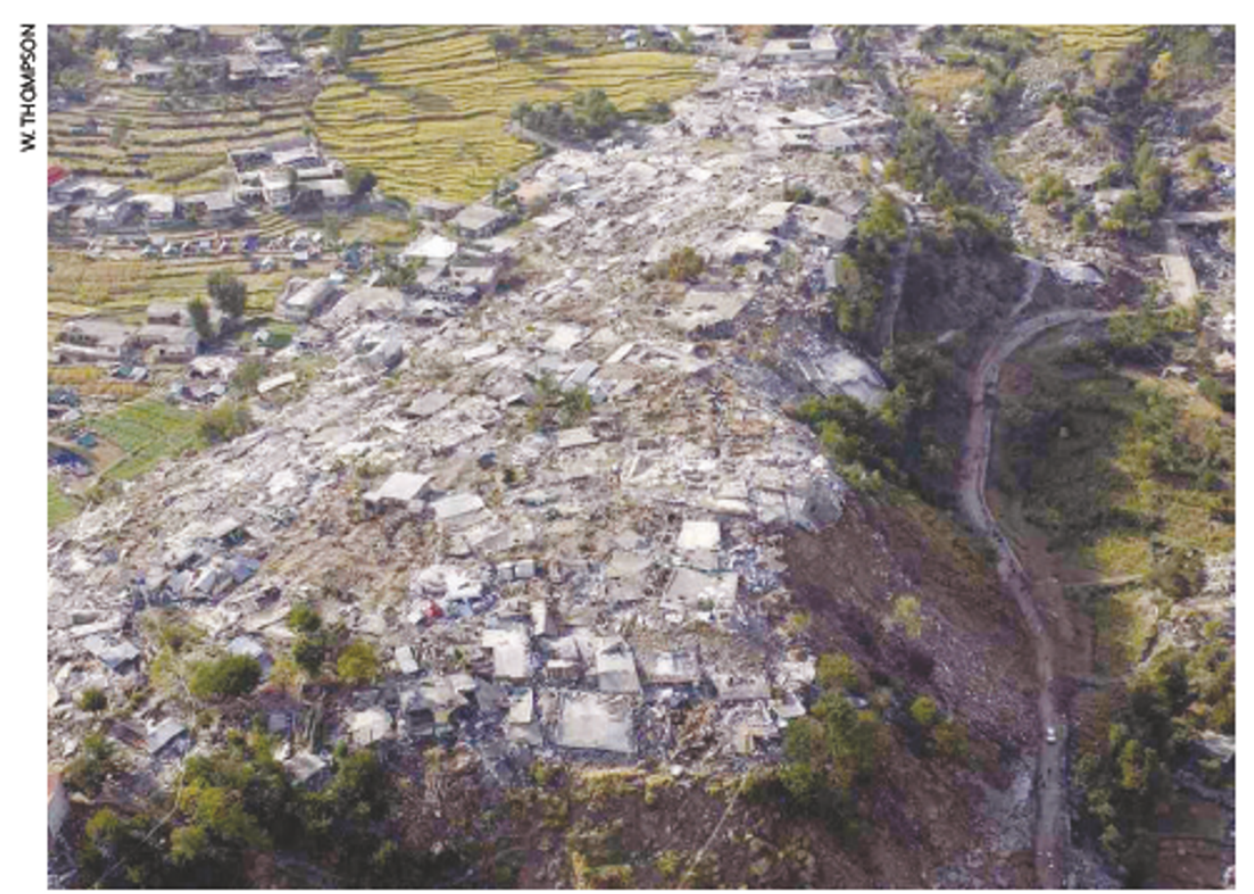

The Kashmir earthquake revealed the inadequacy of Pakistan's building codes and seismological data.

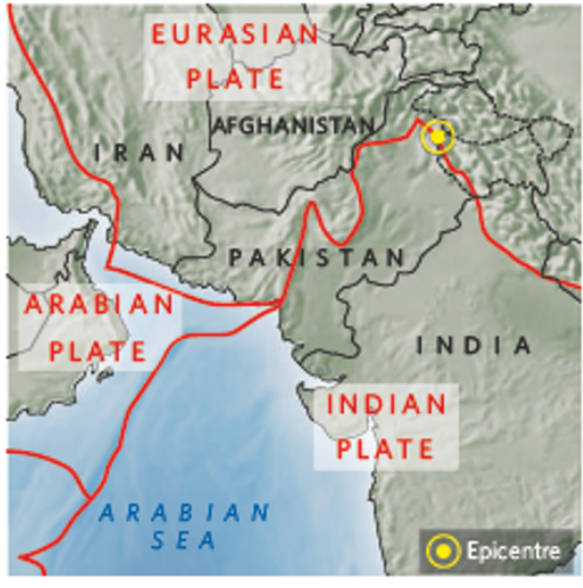

"The paranoia is completely

unfounded. If you want to know

exactly where something is, you can

get a GPS receiver from Wal-Mart." - Roger Bilham

Qamar-Uz-Zaman Chaudhry, director-general of the meteorological department. One main reason, he says, was the army's concern that the data could be used to monitor explosive tests related to the nation's nuclear programme in the lead-up to its 1998 nuclear tests. ${ }^{\alpha}$ Previously there were fears about nuclear monitoring, and that has hampered our cooperation with other countries, Chaudhry says.
Pakistan's army has another reason for secrecy: the country's most active seismic areas are in the contested region of Kashmir. Since the partition of India and Pakistan in 1947 , both countries have laid claim to the region. To this day, roughly 100,000 Indian and Pakistani troops stare at each other across a delicate line of control. Fearing that either side could gain even a tiny edge from geospatial measurements, "both India and Pakistan have said that nobody can do any kind of GPS measurements", says Jack Schroder, a seismologist at the University of Nebraska in Omaha who has worked in Pakistan.

"This paranoia is completely unfounded," contends Roger Billham, a geologist at the University of Colorado, Boulder. "Aerial photographs are available to everybody, maps were left by the British, and if you want to know exactly where something is, you can get a GPS receiver from Wal-Mart. If the government wants to save people, they've got to protect them from earthquakes, not India."

In fact, there are signs that Pakistan's military government is opening up. Immediately after the October quake, government officials asked non-profit groups and relief agencies to remove satellite photos of the affected areas from their websites (see Nature 437, 1072-1073; 2005). But after a brief public outcry, the authorities quickly relented. ${ }^{\star}$ The government and whole country have been awakened," says Umar Faroog, director of the Institute of Geology at the University of the Punjab in Lahore, who has criticized the government for its secrecy.

Chaudhry adds that the government has also begun establishing cooperative agreements with the United States, China, Iran and Japan. These would allow for the exchange of data and equipment, among other things. But Pakistan has yet to establish any working relation with India, which shares many of the same geological faults (see page 1).

Such openness is a positive step, says Julian Bommer, a seismologist at Imperial College in London. But to build an effective model of seismic risk, he says, " $y$ you need to supplement microseismic information with the earthquake history". Knowing the size and frequency of quakes along individual faults gives seismologists a sense of what those faults can produce. Such information, in turn, is a major ingredient of the complex formulae that determine earthquake risks and building codes.

Historical records of earthquakes in the region are spotty at best, Bommer says. To compensate, geologists must travel to individual faults and conduct trenching surveys, which analyse soil for signs of past earthquakes. Trenching is a rough way for geologists 


\section{Portrait of the seismologist as a young woman}

Finding a seismologist in Pakistan is nearly as difficult as find ing a woman working outside the home. So the fact that Mona Lisa (a print hangs in her apartment) is both makes her an anomaly and a symbol of change.

The 33-year-old received her $\mathrm{PhD}$ in earthquake seismology in January from Quaid-i-Azam University in Islamabad, the first full PhD in seismology that a Pakistani university has ever produced, according to colleagues. She was born and raised in Islamabad. Her father was a tax officer with the financeministry and her mother a schoolteacher with a keen interestin the natural world. "My mother had a strong aptitude towards the sciences," Lisa says. "Unfortunately, she didn'tpursue graduate-level studies, so she pushed us instead." By 'us', Lisa means herself and her 11 siblings. Collectively, the family could now bea university department all on its own: as well as Lisa, five brothers hold $\mathrm{PhD}$ s in physics, one sibling has a master's, and two more are pursuing $\mathrm{PhDs}$.

Lisa too originally planned on being a physicist, but when she graduated from Government College in Islamabad, she found herself gravitating towards geology instead. "I liked the variety of courses," she says.

Being a woman in Pakistan's male-dominated society made things difficult. Often themale students would mock Lisa and the other female studentin the programme. Onetime, when the class visited a fault outside of

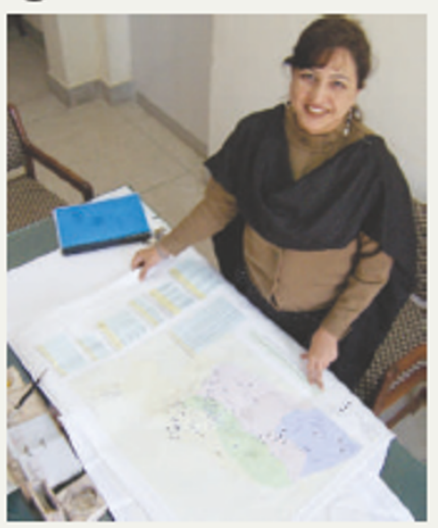

Islamabad, the men refused to stand on the same side of the fault as the women. "Everybody was discouraging us, butby the second semester I stood first in the class," sherecalls with a smile.

Lisa has now completed her thesis, a detailed seismic chart of faults in the region of Kashmir where last October's earthquake struck. The work, which involves measurements and computer modelling, impressed reviewers such as Frank Roth, a seismologist at the National Research Centre for Geosciences in Potsdam, Germany. "She's really hard-working" he says. The only weakness in her thesis, hesays, is a lack of detailed data about the region's seismic history. "But I wouldn't say that's her fault," he adds.

Lisa has now secured a professorship at Quaid-i-Azam University, and she hopes to use her position to start a new seismology programme. "After the earthquake, many students are interested in postgraduate work," she says. "I have strong hopes for trainingthem." to get a sense of the timing and size of earthquakes along a particular fault.

Outsiders alone cannot survey Pakistan's hundreds of faults, says Bommer, who has conducted earthquake-hazard assessments in Greece, Turkey and Iran. "My experience," he says, "is that stuff that's done by flying in and out is often insufficient." In short, a comprehensive assessment of Pakistan will require homegrown talent.

Unfortunately, that talent pool is currently small. The nation of 160 million is home to perhaps half a dozen researchers with $\mathrm{PhDs}$ in seismology and, to date, Pakistan's many universities have produced just a single seismology $\mathrm{PhD}$ on their own, awarded in January (see 'Portrait of the seismologist as a young woman'). The meteorological department has only 15 employees with training in the field, and none have $\mathrm{PhDs}$, says Chaudhry. One employee is now working on a $\mathrm{PhD}$ in China.

The problem is that geology, like so many things in Pakistan, has been driven by the country's economic needs, says Ali of Quaidi-Azam University. "Financially, people did not see a future in the field of seismology," he says. ${ }^{\alpha}$ There were no teachers available, and most of the geophysicists preferred working for an oil company."

This, too, may be changing. At the University of Peshawar, the National Center for Excellence in Geology is ramping up its expertise in seismic studies, says Asif Khan, the centre's director. After the October quake, more students are showing an interest in seismology, and the University of Peshawar recently opened an earthquake-engineering programme. With similar efforts afoot in Lahore and Karachi, Khan predicts that "within three to four years we will have a good number of researchers".
That effort is being complemented by a mammoth investment in higher education. According to Atta-ur-Rahman, chairman of Pakistan's higher education commission, the higher-education budget has risen $1,500 \%$ in three years to roughly US $\$ 190$ million. Much of the money will go towards better university salaries to lure well-trained Pakistani scientists from foreign and industrial jobs.

On top of that, in June 2005 the meteorological department received a government grant, of US\$3.5 million for the first phase of a new national seismic network, a response to the

"Financially, people did not see

a future in seismolology. Most of

the geophysicists preferrered

working for oil companies."

- Khawaja Azam Ali

2004 Indian Ocean tsunami. The network will include broadband seismic stations in Quetta, Karachi and Peshawar, plus regional centres in 14 other cities. In total, it will include more than 100 new monitoring stations. "With this network," says Chaudhry, "we should be able to completely analyse earthquakes in two to three minutes."

Ultimately, however, data and assessments can save lives only if coupled with a massive public-education campaign. That's no mean feat in a country where just over half the population is illiterate.

At present, says Bommer, ${ }^{\alpha}$ Pakistan doesn't even have a seismic building code, which is astounding". As is often the case with major earthquakes, in October most people were killed when shoddily constructed buildings collapsed. A number of simple regulations would make buildings safer, says Bommer. For example, concrete should be mixed with pure sand instead of mixtures of soil and sand, and steel reinforcing rods holding up roofs should be joined to the frame of the house to prevent it from collapsing during shaking.

But there is little money to make such improvements. Resources have been stretched near to breaking point in the aftermath of the October quake - rebuilding is expected to cost $\$ 3.5$ billion. The government's Earthquake Rehabilitation and Reconstruction Authority is overwhelmed by the needs of the millions of people left homeless by the quake, says Mohyuddin Wani, an official with the authority.

Wani says that a new building code is being drawn up in Islamabad, based in large part on assessments by Turkish and Chinese seismological teams that visited Pakistan last November. But whether those codes can be properly distributed and enforced before reconstruction begins seems doubtful. " Pressure is building to begin reconstruction immediately, he says.

In spite of the challenges, many now believe that Pakistan might be on a course to cope with its seismic troubles. But Bilham worries that the fresh efforts to publicize data, educate more geologists and provide new instrumentation could falter as the October disaster fades from the public memory. He argues that the country needs a long-term commitment to seismic safety, as local governments in the western United States have done. "People in Pakistan are just as clever as people in California, ${ }^{\circ}$ he says. "They just havent yet had the opportunity to deal with the problem."

Geoff Brumfiel is Nature's physical science correspondent. 